\title{
Do It and Do It Well: Assessment of Online Teaching in the New Normal among Selected Universities in the Philippines
}

\author{
Rolando A. Alimen1, Perlita R. Israel'2, Ma. Cecilia D. Alimen³, Victor B. Jaleco' \\ ${ }^{1}$ John B. Lacson Foundation Maritime University-Molo, Iloilo, Philippines \\ ${ }^{2}$ Research Department Services, College of Hospitality \& Rural Resource Management, Aklan State University, Ibajay, Aklan, Philippines \\ ${ }^{3}$ University of San Agustin, Iloilo, Philippines \\ Email: ralimen@yahoo.com, mcalimen@usa.edu.ph, jjjaleco@yahoo.com
}

How to cite this paper: Alimen, R. A., Israel, P. R., Alimen, Ma. C. D., \& Jaleco, V. B. (2022). Do It and Do It Well: Assessment of Online Teaching in the New Normal among Selected Universities in the Philippines. Open Journal of Social Sciences, 10, 199-211.

https://doi.org/10.4236/jss.2022.102014

Received: October 7, 2021

Accepted: February 19, 2022

Published: February 22, 2022

Copyright $\odot 2022$ by author(s) and Scientific Research Publishing Inc. This work is licensed under the Creative Commons Attribution International License (CC BY 4.0).

http://creativecommons.org/licenses/by/4.0/

\begin{abstract}
The study evaluates the extent of online teaching among instructors at the selected universities in the Philippines. Furthermore, this study aimed to determine the level of online teaching among instructors as an entire group and when grouped according to the following such as: 1) gender, 2) type of residence, 3) number of years in teaching, 4) age, 5) the highest educational attainment, and 6) area. Moreover, the study explored the respondents' qualitative views, challenges, and comments employing the EL (electronic learning) platforms. The study utilized 120 faculty members from the private and state universities in the Philippines. Participants of this study were classified according to gender, type of residence, number of years in teaching, the highest educational attainment, and areas of specialization. The researchers used quantitative and qualitative research designs. The quantitative research design utilized a Likert-type data instrument and statistical tools used were mean, $t$-test, and Analysis of Variance (ANOVA). The study was submitted and evaluated for its contents by the experts in the qualitative method. Moreover, qualitative data and information will be gathered through the interview to be conducted by the researchers themselves. The experts guided the researchers in the conduct of qualitative process. Results revealed that online teaching was "very high." The challenges derived from the qualitative views and statements experienced by the respondents were the following: 1) interrupted and unstable signal, 2) technical issues in the middle of using, 3) unpreparedness of the respondents as they shared that they need more training and hands-on, and 4) frequent maintenance of e-learning infrastructure.
\end{abstract}




\section{Keywords}

Online Teaching, New Normal, Maritime University

\section{Introduction}

The study of Fatima, Nasreen, Parvez, \& Rahaman (2020) mentioned that Internet is one of the greatest recent advancements in the world of information technology that has become a useful instrument which affects the global village. The use of Internet has the major impact on the students' academic achievement and social life, however, excessive internet usage negatively affects one's physical health, family life, and academic performance (Akhler, 2013). Students used Internet for various purposes such as academic, social communication, and recreation (Balouch, et al. 2019). Asdaque, Khan, \& Rizvi (2010) stressed that the use of Internet influenced academic achievement and performance of students. This means that the more time spent in online study, the more effect could be observed in academic performance. Ivwighreghweta \& Igere (2014) stressed that students considered Internet as a new tool of learning and its importance exceeds the information given by physical library. Furthermore, students still agreed that low speed, power outage, and information overload are the challenges of online learning. Colombo's (2020) study posited that online education is no longer a new phenomenon and in the near future, this method has the potential to exceed the traditional or person-to-person education. This may be because of the extent of its usability as long as there is Internet, students and teachers can access anywhere and anytime. Chen (2020) stressed that teachers are trained to master the mode of networking-teaching, they are trained to do it in a very constructive way. Using different online platforms, teachers' level of teaching was improved, changed, and enhanced. It was in this study that the author found out the positive correlations among the teachers' adaptability, teachers' attitude, and teaching effectiveness.

The present study aimed to evaluate the extent of online teaching using the different online platforms among instructors at the selected universities in the Philippines. Specifically, this study sought to answer the following specific questions:

1) What is the level of online teaching among instructors at the selected universities as an entire group and when grouped according to the following such as: a) gender, b) type of residence, c) number of years in teaching, d) age, e) the highest educational attainment, and f) areas of specialization?

2) Are there significant differences in the online teaching when the respondents were grouped according to different categories such as a) gender, b) location of residence, c) number of years in teaching, d) age, e) the highest educational attainment, and $\mathrm{f}$ ) area?

3) What are the views and comments of the respondents about online teaching? 
4) What are the challenges encountered and suggestions of the respondents using online teaching?

\section{Hypotheses}

There are no significant differences in the assessment of online teaching when the respondents were grouped according to different categories such as 1) gender, 2) location of residence, 3) number of years in teaching, 4) age, 5) the highest educational attainment, and 6) department.

\section{Related Literature and Studies}

The present study included some related studies in the fields particularly in using the online learning and teaching. The study conducted by Xiao, Zhang, $\& \mathrm{Pu}(2021)$ mentioned that online teaching platform of the colleges and universities is one of the important contents of Internet education platforms, this is considered as urgent requirement for the online information construction among colleges and universities to build favorable online platform and to adapt to the new challenges of education. The advantages of this online teaching platform were the self-study at any place and clouding, while the disadvantages were network bandwidth, Internet connectivity, and teachers' and students' literacies.

Another study by Xie, Qui, Huang, \& Wang (2020) underscored that urgency of online education have been considered at the highest level and online education had become the focus of the study of the different groups, communities, and institutions.

Study conducted by Alagsam et al. (2021) stressed that researchers should conduct studies on online tool-assessment and integrating it in the online learning environment. The authors mentioned the different areas of studies such as: online learning materials, designed software, online platform, online websites, and online courses.

Yang (2021) discussed that online learning management and academic performance are beneficial for teachers and administrators in order to understand the whole process of online general education, types of learning, and students' characteristics in order to provide personalized learning and support service with high quality educational system.

Another study conducted by $\mathrm{Hu}$ et al. (2020) agreed that during this pandemic online teaching is used by the schools and universities, which the result stated that most of the students in this particular study were satisfied with the teaching method, specifically in dealing with online teaching of electronics engineering.

However, in the study of Yang et al. (2020) revealed that various problems and emergencies kept on happening in the online platforms and Internet connectivity of students and teachers in the colleges and universities.

Conceptual and Theoretical Frameworks

The relationships of the different variables in this study are presented in Fig- 
ure 1.

The illustration in Figure 1 indicates that online teaching may influence by teachers-related factors such as gender, type of residence, and number of years in teaching, age, highest educational attainment, and area of specialization.

The study was anchored on the Constructivism Theory of Teaching by Jia (2010), which states that the roles of teachers should shift from initiator, helper, and driver for the students' development. Teacher must be designer of teaching environment, academic consultant, and help students to form technique, attitude, and habits in learning. This theory focuses on improving students' comprehensive quality learning. The teachers' experiences in drawing cooperation and communication were the important factors leading to build the students' knowledge system, cultivate innovative spirit and problem solving abilities. This theory brings new insights, views, and challenges to the teachers engaging in the online teaching in order to create better quality teaching environment.

\section{Method}

The researchers used quantitative and qualitative research designs. The quantitative research design utilized a Likert-type data instrument and statistical tools used were mean, $t$-test, and Analysis of Variance (ANOVA). Moreover, the quantitative and qualitative information and statements were analyzed using the mixed method (Dawadi, Shrestha, \& Giri, 2021; Poth \& Munce, 2020), this method integrates philosophical frameworks of both post-positivism and interpretivism, interweaving qualitative and quantitative data in such a way that research issues are meaningfully explained. This enables the researchers to answer questions with sufficient depth and breadth and helps generalized findings of the whole issues. Furthermore, this method is used to address impact of research questions integrated and synergized in order to answer complex problems. The qualitative design process was guided by the qualitative and qualitative experts and was based on a qualitative framework by Creswell (2012).

\section{Respondents of the Study}

The study utilized the 120 faculty members from the different universities in the Philippines for SY 2020-2021. Participants of this study were classified according to gender, type of residence, number of years in teaching, highest educational attainment, and department.

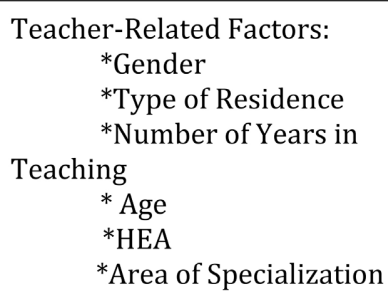

Online Teaching:

Figure 1. The diagram shows the online teaching as influenced by teacher-related factors. 
The distribution of the respondents according to different categories is reflected in Table 1.

\section{Results of the Study}

As shown in the Table 2, the results of online teaching of the respondents as an entire group and when categorized according to different categories such as gender (male and female), residence (rural and urban), number of years (10 years \& below, 11 years - 20 years, and 21 years and above), age (30 years and below and 31 years $\&$ above), highest educational attainment (master's \& doctorate degrees), and areas of specialization (professional, business, general education)are "very high" as indicated by the following mean scores of 4.40, 4.46, 4.34, $4.36,4.45,4.51,4.42,4.19,4.76,4.36,4.47,4.30,4.38,4.35$, and 4.56 respectively.

Differences in the Use of Online Teaching

Table 1. Profile of the respondents.

\begin{tabular}{|c|c|c|}
\hline Category & $\mathrm{f}$ & $\%$ \\
\hline Entire Group & 120 & 100 \\
\hline \multicolumn{3}{|l|}{ Gender } \\
\hline Male & 68 & 57 \\
\hline Female & 52 & 43 \\
\hline \multicolumn{3}{|l|}{ Residence } \\
\hline Rural & 60 & 50 \\
\hline Urban & 60 & 50 \\
\hline \multicolumn{3}{|l|}{ Number of years teaching } \\
\hline 10 years and below & 46 & 38 \\
\hline 11 years - 20 years & 48 & 40 \\
\hline 21 years and above & 26 & 22 \\
\hline \multicolumn{3}{|l|}{ Age } \\
\hline 30 years old and below & 38 & 32 \\
\hline 31 years old and above & 82 & 68 \\
\hline \multicolumn{3}{|c|}{ Highest Educational Attainment } \\
\hline Master's Degree & 74 & 62 \\
\hline Doctorate Degree & 46 & 38 \\
\hline \multicolumn{3}{|l|}{ Area } \\
\hline Marine/Prof & 56 & 47 \\
\hline Business & 42 & 35 \\
\hline Gen Education & 22 & 18 \\
\hline
\end{tabular}


Table 2. Level of online teaching.

\begin{tabular}{|c|c|c|c|}
\hline Category & M & $\mathrm{SD}$ & Description \\
\hline Entire Group & 4.40 & 0.54 & Very High \\
\hline \multicolumn{4}{|l|}{ Gender } \\
\hline Male & 4.46 & 0.54 & Very High \\
\hline Female & 4.34 & 0.54 & Very High \\
\hline \multicolumn{4}{|l|}{ Residence } \\
\hline Rural & 4.36 & 0.54 & Very High \\
\hline Urban & 4.45 & 0.54 & Very High \\
\hline \multicolumn{4}{|l|}{ Number of years teaching } \\
\hline 10 years and below & 4.51 & 0.51 & Very High \\
\hline 11 years - 20 years & 4.42 & 0.55 & Very High \\
\hline 21 years and above & 4.19 & 0.54 & High \\
\hline \multicolumn{4}{|l|}{ Age } \\
\hline 30 years old and below & 4.76 & 0.46 & Very High \\
\hline 31 years old and above & 4.36 & 0.53 & Very High \\
\hline \multicolumn{4}{|c|}{ Highest Educational Attainment } \\
\hline Master's Degree & 4.47 & 0.50 & Very High \\
\hline Doctorate Degree & 4.30 & 0.60 & Very High \\
\hline \multicolumn{4}{|l|}{ Area of Specialization } \\
\hline Marine/Professional & 4.38 & 0.58 & Very High \\
\hline Business & 4.35 & 0.50 & Very High \\
\hline General Education & 4.56 & 0.52 & Very High \\
\hline
\end{tabular}

Legend: Scale: Description; 4.21 - 5.0: Very High; 3.41 - 4.20: High; 2.61 - 3.40: Average; 1.81 - 2.60: Low; 1.00 - 1.80: Very Low.

Table 3 presents the $t$-test results of the level of assessment of online teaching using different EL (Electronic Learning) platforms of the respondents when grouped according to gender, residence, age, and highest educational attainment. Results revealed that there are no significant differences in the level of assessment on online teaching according to gender with $t(118)$ value of $-0.457 \&$ $p>0.05$, residence with $t(118)$ value $=-0.715$ and $p>0.05$, age with $t$ (118) value $=0.665 \& p<0.05$, and highest educational attainment with $t(118)$ value $=$ $0.882 \& p<0.05$. Therefore, null hypotheses that state "there are no significant differences in the assessment of online teaching when the respondents were grouped according to different categories such as 1) gender, 2) type of residence, 3) age, and 4) highest educational attainment" are all accepted.

Data are shown in Table 3. 
Table 3. $t$-test results in the level of assessment of online teaching using different el when grouped according to gender, residence, age, and highest educational attainment.

\begin{tabular}{llcccc} 
Category & M & $\begin{array}{c}t \\
\text { value }\end{array}$ & df & $\begin{array}{c}2 \text {-Tailed } \\
\text { Significance }\end{array}$ \\
\hline
\end{tabular}

1) Gender

$\begin{array}{ccccc}\text { Male } & 4.46 & & & \\ \text { Female } & 4.36 & -0.848 & 118 & 0.457\end{array}$

2) Residence

$\begin{array}{lllll}\text { Rural } & 4.36 & & & \\ \text { Urban } & 4.45 & -0.656 & 118 & 0.715\end{array}$

3) Age

$\begin{array}{lllll}30 \text { yrs old \& below } & 4.76 & & & \\ 31 \text { yrs old \& above } & 4.36 & 1.884 & 118 & 0.665\end{array}$

4) Highest Educational Attainment

$\begin{array}{ccccc}\text { Master's Degree } & 4.47 & & & \\ \text { Doctorate Degree } & 4.30 & 1.236 & 118 & 0.882\end{array}$

$p<0.05$.

ANOVA Results of Online teaching when the respondents were grouped according to Number of Years in Teaching

The ANOVA results in Table 4 indicated that the respondents did not differ significantly in their online teaching when classified according to number of years such as 10 years and below, 11 to 20 years, and 21 years and more as indicated by $\mathrm{F}(2,117)=1.48, p>0.05$.

ANOVA Results of Online teaching when the respondents were grouped according to Different Areas of Specialization

The ANOVA results in Table 5 revealed that no significant differences in the respondents' areas of specialization when grouped according to marine/professional, business, and general education as reflected in the $\mathrm{F}(2,117)=1.828$ with $p>$ 0.05 .

\section{Qualitative Findings and Discussion}

The researchers gathered the respondents' views about online teaching, these views are centered on the three statements such as the following: challenging (35\% of the respondents), enjoyable (35\% also), and satisfying (30\%) as indicated in Figure 2.

From the richness and thickness of the statements and views by the respondents, four (4) interesting themes emerged relative to comments on online teaching. These include: (1) helpful and good tool for students' learning, innovative and appropriate teaching method/strategy, and need more time to explore/training, of which these ranked first, and followed by (2) improvement of the system.

Data are shown in Table 6. 


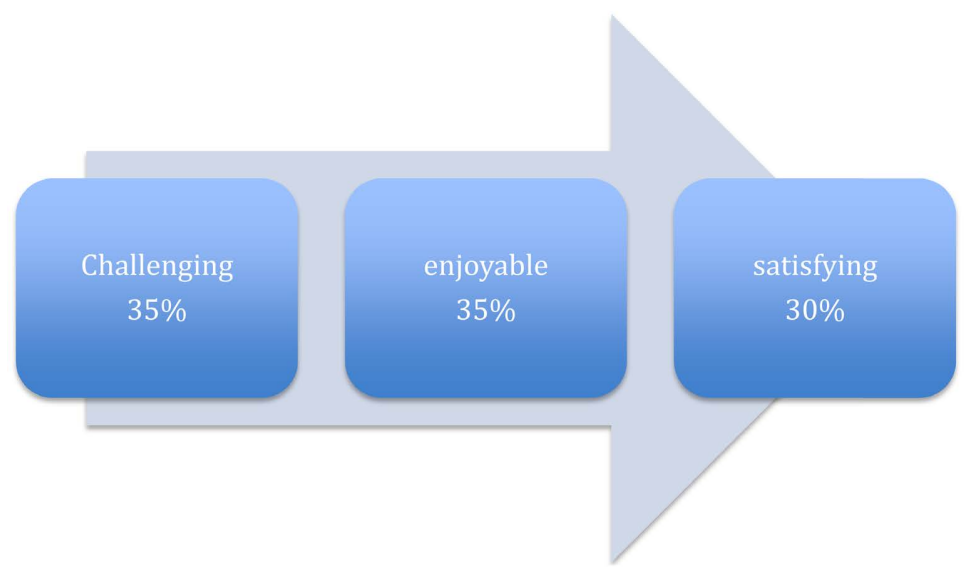

Figure 2. Respondents' views of online teaching.

Table 4. One-Away ANOVA Results of Online teaching when the respondents were grouped according to Number of Years in Teaching.

\begin{tabular}{cccccc}
\hline Source of Variance & Sum of Squares & df & Mean Square & F & Sig \\
\hline Between Groups & 14.89 & 2 & 1.267 & 1.48 & 0.575 \\
Within Groups & 99.33 & 117 & 0.720 & & \\
Total & 114.22 & 119 & & & \\
\hline
\end{tabular}

Table 5. ANOVA when grouped according to areas.

\begin{tabular}{cccccc}
\hline Source of Variance & Sum of Squares & df & Mean Square & F & Sig \\
\hline Between Groups & 15.77 & 2 & 1.526 & 1.828 & 0.896 \\
Within Groups & 118.42 & 117 & 0.522 & & \\
Total & 34.18 & 119 & & & \\
\hline
\end{tabular}

Table 6. Respondents' comments about online teaching.

\begin{tabular}{cccc}
\hline Comments on Online teaching using JEL & F & $\%$ & $\mathrm{R}$ \\
\hline Helpful and good tool for students' learning & 31 & 26 & 2 \\
Innovative \& appropriate teaching method/strategy & 31 & 26 & 2 \\
Need more time to explore/training & 31 & 26 & 2 \\
Improvement of the system & 27 & 22 & 4 \\
Total & 120 & 100 & \\
\hline
\end{tabular}

\section{1) Helpful and Good tool for Students' Learning}

Interestingly, one of the themes emerged from the views of the respondents that online teaching is "helpful and good tool for students' learning" as supported by the one of the statements of the respondents, which stated as "online is very helpful in the learning process of the students".

Another respondent mentioned: "this modality should be embraced as this is 
the only appropriate and applicable tool for learning during this time of pandemic."

One of the respondents' comment "it is one of effective platforms for online teaching, it is good and easy to use, and making my preparations easier".

Online teaching using JEL is crucial to the academic performance of the students. This may mirror the kind of teaching delivery that teacher would employ in his class. The use of this online platform-JEL is one of the indicators of the instructor's adherence to attain standards of teaching in the university in the midst of this pandemic.

\section{2) Innovative and Appropriate Teaching Method}

Some people may state that the "teacher could be identified the way he teach," it appears that the respondents considered this "Online teaching" as "innovative and appropriate teaching method." Students find this method as appropriate and excellent for the sake of catering students' needs in terms of learning in the university. The comments on online teaching as "innovative and appropriate teaching method" are supported by the following statements:

"very appropriate teaching method under this pandemic";

"good innovation, it is easier to track the objectives of the lessons and quizzes";

"user friendly, it is easy to access and provides relevant functions as needed".

\section{3) Need more time to explore/training}

This theme was supported by the few statements such as:

"need more time to explore the JEL";

"there was a difficult before due to some barriers in communication";

"only applicable to those who are living in urban areas.

\section{4) Improvement of the system}

This comment is reflected by some of the respondents' statements:

"the performance of JEL sometimes is not good";

"sometimes, there is a system error";

"maintenance of JEL should be scheduled during no class, exams, and activities.

\section{Challenges of Online Teaching}

The respondents shared the following challenges in dealing with online teaching: interrupted and unstable signal $(f=45, R=1)$, technical issues $(f=25$, $R=2$ ), unpreparedness of users or teachers ( $f=15, R=3.5$ ), and offline connection due to maintenance $(\mathrm{f}=15, \mathrm{R}=3.5)$ as shown in Table 7 and Figure 3.

Data are shown in Table 7.

\section{Suggestions in order to Improve Online Teaching}

After processing all the qualitative suggestions of the respondents, majority agreed on the following with regards to the use of different online platforms in conducting online classes: 1 ) upgrading of the Internet $(50 \%, \mathrm{R}=1), 2)$ training of the faculty members to further familiarize with EL (electronic learning) (30\%, $\mathrm{R}=2)$, and 3$)$ monitoring of Internet connectivity $(20 \%, \mathrm{R}=3)$ as shown in Table 8. 


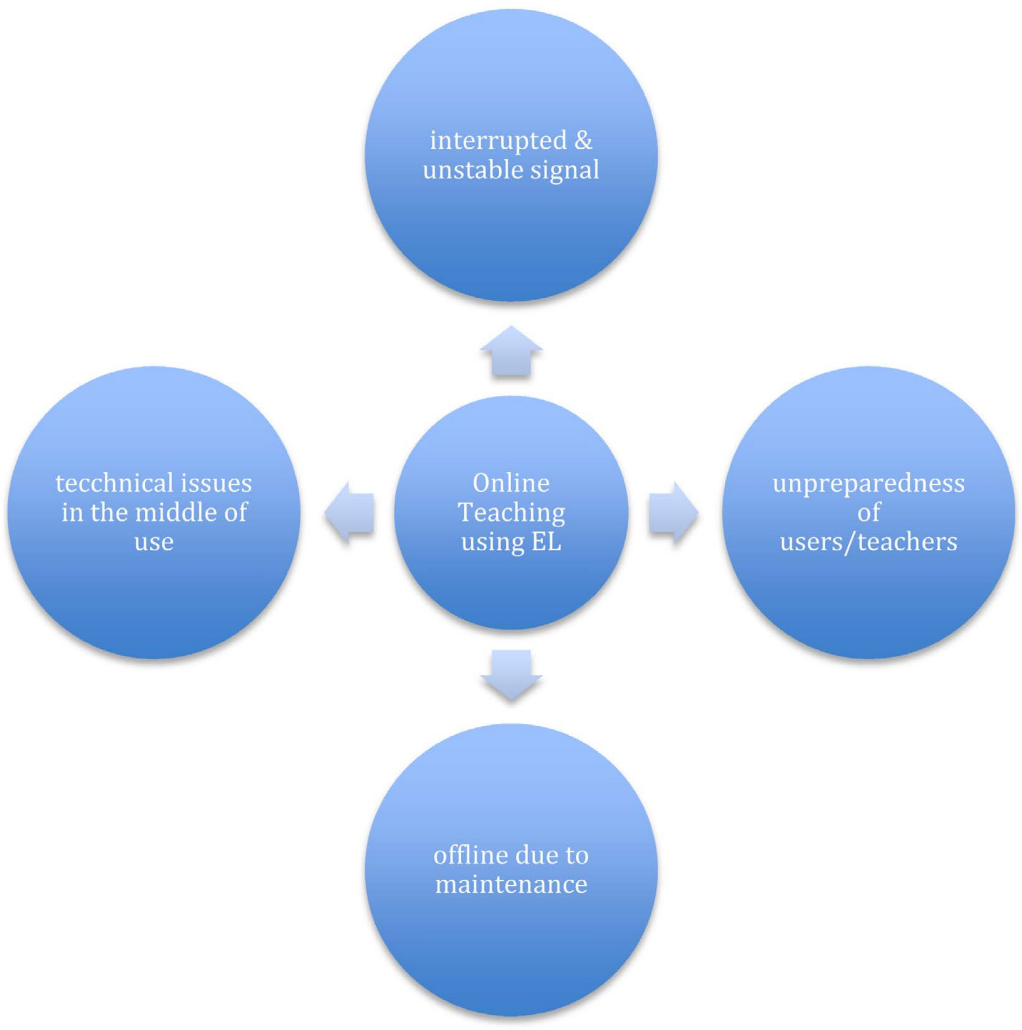

Figure 3. Challenges of online teaching.

Table 7. Challenges of online teaching.

\begin{tabular}{ccc}
\hline Challenges & $\%$ & $\mathrm{R}$ \\
\hline Interrupted \& unstable signal in starting the class & 45 & 1 \\
Technical issues in the middle of online class & 25 & 2 \\
Unpreparedness of the users/teachers & 15 & 3.5 \\
Offline due to maintenance of JEL & 15 & 3.5 \\
\hline
\end{tabular}

Table 8. Suggestions of the respondents in order to improve the online teaching.

\begin{tabular}{cccc}
\hline Suggestions of the Respondents & $\%$ & $\mathrm{R}$ \\
\hline Upgrading of the Internet & 50 & 1 \\
Training of the faculty members to further familiarize the applications & 30 & 2 \\
Monitoring of the Internet Connectivity & 20 & 3 \\
\hline
\end{tabular}

\section{Summary of Findings}

This study revealed the following findings:

1) The results of online teaching of the respondents as an entire group and when categorized according to different categories such as gender (male and female), residence (rural and urban), number of years (10 years \& below, 11 years - 20 years, and 21 years and above), age (30 years and below and 31 years \& 
above), the highest educational attainment (master's \& doctorate degrees), and areas of specialization (professional, business, general education) are "very high".

2) There are no significant differences in the assessment of online teaching when the respondents were grouped according to different categories such as a) gender, b) type of residence, c) age, and d) the highest educational attainment.

3) The views of the respondents about online teaching were: helpful and good tool for students' learning, innovative and appropriate teaching method/strategy, and need more time to explore/training, of which these ranked first, and followed by improvement of the system.

4) The challenges in dealing with online teaching were the following: interrupted and unstable signal, technical issues, unpreparedness of users or teachers, and offline connection due to maintenance.

5) The qualitative suggestions of the respondents with regards to the use of different online platforms in conducting online classes were: upgrading of the Internet, training of the faculty members to further familiarize with EL (electronic learning), and monitoring of Internet connectivity.

\section{Conclusion}

Based on the findings of the study, the conclusions were advanced:

The very high results of the assessment of the respondents on online teaching using JEL were influenced by the concerns and aims of the administrations of the selected universities in helping the instructors in using this new method of teaching in the midst of pandemic.

The results on "no significant differences" existed in the assessment of online teaching using different EL platforms which means that categories of the respondents do not influenced the favorable level of assessment of the instructors. It means further that male and female instructors considered this "electronic online platform" as a new method of teaching and very useful to them to deliver the intended-learning objectives (ILO) and achieve the objectives of their lessons through their teaching-methods.

\section{Recommendations}

After analyzing and interpreting the results of the data and framing the conclusions of this particular study, the researchers would suggest the following:

1) The administrators of the universities involved in this study should sustain the favorable results of assessment of online teaching using the JEL by the instructors.

2) Qualitative statements and views of the respondents should have course of action in order to improve the delivery of online teaching of the instructors.

3) The results of this study should be discussed in the academic council meetings in order to improve the online-instructional delivery of the faculty members. 
4) The suggestions and recommendations of the faculty members should also be part of the academic course of action.

5) The researchers suggested for parallel studies to determine the other factors that influenced online teaching, which are not included in this present study.

\section{Conflicts of Interest}

The authors declare no conflicts of interest regarding the publication of this paper.

\section{References}

Akhler, N. (2013). Relationship between Internet Addiction and Academic Performance among University Undergraduates. Journal of Sciences Technology Education Research, 8, 1793-1796.

Alagsam, A., Ghabban, F., Ameerbakhsh, O., Alfadli, I., \& Fayez, A. (2021). Current Trends in Online Programming Languages Learning Tools: A Systematic Literature Review. Journal of Software Engineering and Applications, 14, 277-297. https://doi.org/10.4236/jsea.2021.147017

Asdaque, M., Khan, M. N., \& Rizvi, D. (2010). Effect of Internet on the Academic Performance and Social Life of University Students in Pakistan. Journal of Education and Sociology, 12, 21-27.

Balouch, D., Anwar, D., Amsari, M., Rasheed, D., Siddique, M., \& Balouch, D. (2019). Impact of Online Social Networking on Mental Health among Medical Students of LUMHS Jamshoro, Sindh, Pakistan. Rawal Medical Journal, 44, 613-617.

Chen, R. (2020). Study on the Influencingh Factors of Teaching Effect of Universityu Teachers during the Period of Pandemic. Open Access Library Journal, 7.

Colombo, R. (2020). Teaching a Synchronous Online Business Organizations Course to J.DF. Students: A Case Study. Hofstra Law Review: Summer 2020, 48, 873-940.

Creswell, J. W. (2012). Educational Research: Planning, Conducting, and Evaluating Quantitative and Qualitative Research (4th Ed.). Pearson.

Dawadi, S., Shrestha, S., \& Giri, R. (2021). Mixed-Methods Research: A Discussion on Its Types, Challenges, and Criticisms. Journal of Practical Studies in Education, 2, 25-36. https://doi.org/10.46809/jpse.v2i2.20 https://www.jpse.gta.org.uk

Fatima, K., Nasreen, S., Parvez, S., \& Rahaman, A. (2020). Impact of Using the Internet on Students: A Sociological Analysis at Bangabandhu Sheikh Mujibur Rahman Science and Technology University, Gopalganj, Bangladesh. Open Journal of Social Science, 8 , 71-83. https://doi.org/10.4236/jss.2020.812007

Hu, H., Song, S., Chai, Y., \& Gong, Y. (2020). Study on Online Teaching of High Frequency Circuit under COVID-19 Epidemic. Open Journal of Social Sciences, 8, 493-496. https://doi.org/10.4236/jss.2020.83041

Ivwighreghweta, O. \& Igere, M.A. (2014). Impact of the Internet on Academic Performance of Students in Tertiary Institutions in Nigeria. Journal of Information and Knowledge Management, 5, 47-56.

Jia, Q. (2010). A Brief Study on the Implication of Constructivism Teaching Theory on Classroom Teaching Reform in Basic Education. International Education Studies, 3, 197-199. https://doi.org/10.5539/ies.v3n2p197

Poth, C. \& Munce, S. E. P. (2020). Commentary-Preparing Today's Researchers for a 
Yet Unknown and Sustainable Mentoring Approach to Mixed Methods Research Learning. International Journal of Multiple Research Learning Approaches, 12, 56-64. https://doi.org/10.29034/ijmra.v12n1commentary

Xiao, X., Zhang, G., \& Pu, H. (2021). New Thoughts on the Construction of College Online Teaching Platform Adapting to Large Concurrent Access. Creative Education, 12, 1047-1056. https://doi.org/10.4236/ce.2021.125077

Xie, Y. R., Qui, Y., Huang, Y. L., \& Wang, Q. L. (2020). Characteristics, Problems, and Innovation of Online Teaching Mode of "No Suspension of Classes" during Epidemic Prevention and Control. Research on Electronic Education, No. 3, 20-28.

Yang, et al. (2020). Online Teaching Practice and Experience during the Epidemic. China Audio Visual Education, No. 4, 29.

Yang, Y. (2021). Does Greater Engagement in Online General Education Courses Lead to Better Academic Performance Evidence from Chinese University Students. Open Journal of Social Sciences, 9, 298-315. https://doi.org/10.4236/jss.2021.96022 